\title{
Fibrinogen and base excess levels as predictive markers of the need for massive blood transfusion after blunt trauma
}

\author{
Takehiro Umemura $^{1}$ - Yoshihiko Nakamura ${ }^{1} \cdot$ Takeshi Nishida $^{1} \cdot$ Kota Hoshino $^{1}$. \\ Hiroyasu Ishikura ${ }^{1}$
}

Received: 5 February 2015 / Accepted: 15 July 2015 / Published online: 3 November 2015

(C) The Author(s) 2015. This article is published with open access at Springerlink.com

\begin{abstract}
Background Assessment blood consumption and traumaassociated severe hemorrhage scores are useful for predicting the need for massive transfusion (MT) in severe trauma patients. However, fibrinogen (Fbg) and base excess (BE) levels might also be useful indicators for the need for MT. We evaluated the accuracy of prediction for MT of the scoring system vs. Fbg and BE.

Methods The subjects of this retrospective single center observational study were patients with injury severity score $\geq 16$ trauma, divided into a non-MT group and an MT group. We compared variables, including the scoring system (comprising vital signs and focused assessment with sonography for trauma; FAST) and Fbg between the groups. We then performed a multiple logistic regression modeling and a receiver operating characteristic analysis to clarify which value was the most useful predictive indicator for MT.

Results There were 114 patients in the non-MT group and 39 in the MT group. The level of Fbg and BE were
\end{abstract}

Hiroyasu Ishikura

ishikurah@fukuoka-u.ac.jp

Takehiro Umemura

takeume777@gmail.com

Yoshihiko Nakamura

pdmxy827@yahoo.co.jp

Takeshi Nishida

bushinishitaxi007@gmail.com

Kota Hoshino

hoshinoqq@yahoo.co.jp

1 Department of Emergency and Critical Care Medicine, Faculty of Medicine, Fukuoka University, 7-45-1 Nanakuma, Jonanku, Fukuoka 814-0180, Japan independent predictors of MT. The area under the curve values for Fbg and BE were 0.765 and 0.845 , respectively, and the optimal cutoff values of Fbg and BE were $211 \mathrm{mg} /$ $\mathrm{dL}$ and -1.4 , respectively.

Conclusions Fbg and BE levels can be used as an independent predictor for MT.

Keywords Massive transfusion - Fibrinogen level ·

Scoring system $\cdot$ Blunt trauma patients

\section{Introduction}

Trauma is a leading cause of death in persons under the age of 40 and severe hemorrhage is a major cause of mortality in both civilian and military trauma [1-3]. Death from traumatic exsanguination usually occurs rapidly, typically in the first 6-12 h [4-6]. Approximately $10 \%$ of these injured patients are transfused with one or more units of blood, and up to $30 \%$ require a massive transfusion (MT), defined as 10 or more units of blood, in the first $24 \mathrm{~h}$ after admission [7, 8]. However, there are few simple criteria to predict the need for a massive transfusion (MT) in severe trauma patients. As previously reported, the assessment blood consumption (ABC) [9] and trauma-associated severe hemorrhage (TASH) [10] scoring systems are useful predictors of the need for MT. However, these scoring systems require the assessment of several factors, such as vital signs, focused assessment with sonography for trauma (FAST), pelvic fracture and/or femur fracture, making them slightly complicated. Therefore, we need to find some useful biomarkers for TM, which are easy to use in the emergency department.

Routine laboratory-based coagulation tests, such as prothrombin time/international normalized ratio (PT/INR), 
activated partial thromboplastin time (APTT) and fibrinogen $(\mathrm{Fbg})$, platelet count, and hemoglobin $(\mathrm{Hb})$ concentration are used to assess the patient's coagulation status [11]. Schreiber et al. [12] reported that, in military casualties, coagulopathy was identified as a factor contributing to the need for MT. However, when severe bleeding occurs during surgery, coagulation factors do not decrease in a predictable manner. Conversely, it was recently reported that the Fbg level decreased earlier than other blood coagulation factors [13-15]. Stinger et al. [16] reported that the Fbgto-Packed red blood cells (PRBCs) ratio (F/R) was independently associated with mortality [odds ratio (OR) 0.37 , $95 \%$ confidence interval (CI) $0.171-0.812, p=0.013]$, and that the incidence of death from hemorrhage was significantly higher in the low-F/R ratio group than in the highF/R ratio group, with mortality rates of $85 \%$ (23/27) vs. $44 \%$ (21/48), respectively, $p<0.001)$. They suggested that Fbg might play an important role in mortality and predict the need for MT. On the other hand, Kudo et al. reported that the Fresh frozen plasma (FFP)-to-PRBCs ratio during the first $6 \mathrm{~h}$ of admission might not affect mortality or morbidity [17]. Thus, there is not yet a unified view about whether Fbg administration affects the morbidity and mortality of severe trauma patients. Moreover, to our knowledge, there has been no investigation to define the optimal plasma Fbg level that would indicate if MT is required.

Based on the finding that base excess (BE) was a useful predictor of the need for volume replacement in trauma patients [18], this is now widely used in the evaluation of patients who have suffered severe trauma. We conducted the present study to evaluate the usefulness of other predictors of MT in comparison with previous scoring systems, such as the ABC and TASH scores, in patients with blunt trauma.

\section{Methods}

This single center, retrospective study was conducted at Fukuoka University Hospital between June 2009 and December 2011. The study protocol was approved by the institutional review board of Fukuoka University Hospital according to the Declaration of Helsinki. Informed consent was waived in view of the retrospective and anonymous nature of the study. We enrolled blunt trauma patients with an injury severity score (ISS) $\geq 16$ who were admitted to the hospital. MT was defined as the transfusion of 10 units or more of PRBCs in the first $24 \mathrm{~h}$ after admission. In Japan, one unit of PRBC represents a volume of about $120 \mathrm{~mL}$. Patients who were expected to require more than 10 units of PRBC within $24 \mathrm{~h}$, but did not survive for $24 \mathrm{~h}$ due to uncontrolled bleeding, were enrolled in the MT group to reduce survivor bias. The reason we enrolled these three patients in the MT group was based on the criteria of previous studies $[19,20]$ for the grouping of patients.

After allocating patients to an MT group or a non-MT group, we compared the two groups for age, sex, type of trauma (penetrating or blunt), ISS, Glasgow coma scale (GCS), systolic blood pressure (SBP) $(\mathrm{mmHg})$, heart rate (HR) (/min), respiratory rate (RR) (/min), unstable pelvic fracture (UPF), femur fracture open/dislocated (FF $\mathrm{O} / \mathrm{D})$, FAST positive rate, hemoglobin $(\mathrm{Hb})(\mathrm{g} / \mathrm{dL}), \mathrm{BE}$ (mmol/L), ABC [9] and the TASH [10] scores, and Fbg level (mg/dL), INR, APTT (s), blood transfusion, operative management rate, and interventional radiology (IVR) at the time of admission. We also compared the $24 \mathrm{~h}$ and 28-day mortality rates between the groups and evaluated the usefulness of predictors for MT using logistic regression analysis.

\section{Blood samples}

Blood samples were collected at the time of arrival at the ER and before the administration of fluids. Whole blood was collected with sodium citrate as an anticoagulant, in a conventional blood collection tube (NIPRO, Osaka, Japan). Several hemostatic markers, including the Fbg level, were measured within an hour after collection.

\section{Statistical analysis}

Continuous variables are presented as the median and interquartile range (IQR). We used the Chi-square test (or Fisher's exact test, whichever was appropriate) or the Wilcoxon test to compare the two groups. To identify the risk factors for MT, we performed univariate and multiple logistic regression modeling. A receiver operating characteristic (ROC) analysis was done to establish the most useful MT predictor. The Youden index was used to identify the cutoff values for levels of Fbg, BE, ABC score and TASH score, which may have MT significance. All analyses were calculated by the $\mathrm{JMP}^{\circledR}$ version 10 (SAS institute, Tokyo, Japan). $p$ values less than 0.05 were considered significant.

\section{Results}

We enrolled 153 patients who had suffered severe blunt trauma within the given investigation period. There were 114 patients in the non-MT group and 39 patients in the MT group. Table 1 summarizes their demographic and clinical characteristics. Three patients who we included in the MT group were transfused with less than 10 units of PRBCs but died of uncontrolled massive bleeding within $24 \mathrm{~h}$. The massive bleeding was from severe hemothorax in 
Table 1 Demographics and clinical characteristics of blunt trauma patients who did not need massive blood transfusion vs. those who did

\begin{tabular}{|c|c|c|c|}
\hline Variables & Non-MT group $(n=114)$ & MT group $(n=39)$ & $p$ value \\
\hline Age, median (IQR) & 58 (32 to 69$)$ & 57 (37 to 77$)$ & NS \\
\hline Male $(\%)$ & 72.8 & 48.7 & $<0.01$ \\
\hline Glasgow coma scale, median (IQR) & $14(12$ to 15$)$ & $13(7$ to 14$)$ & $<0.05$ \\
\hline SBP $(\mathrm{mmHg})$, median (IQR) & $130(108$ to 151$)$ & $109(84$ to 146$)$ & $<0.01$ \\
\hline RR/min, median (IQR) & 20 (18 to 24$)$ & 24 (17 to 28$)$ & $<0.05$ \\
\hline HR/min, median (IQR) & $84(68$ to 95$)$ & 103 (85 to 122$)$ & $<0.0001$ \\
\hline ISS, median (IQR) & $22(17$ to 25$)$ & 27 (22 to 34$)$ & $<0.01$ \\
\hline FAST positive $(\%)$ & 12.3 & 33.3 & $<0.01$ \\
\hline $\mathrm{Hb}(\mathrm{mg} / \mathrm{dL})$, median (IQR) & $13.4(11.6$ to 15$)$ & $11.3(9.2$ to 12.9$)$ & $<0.0001$ \\
\hline $\mathrm{BE}(\mathrm{mmol} / \mathrm{L})$, median $(\mathrm{IQR})$ & $0.1(-1.7$ to 1.0$)$ & $-3.8(-9.3$ to -1.7$)$ & $<0.0001$ \\
\hline Unstable pelvic fracture $(\%)$ & 5.3 & 25.6 & $<0.001$ \\
\hline Femur fracture open/dislocated (\%) & 4.4 & 12.8 & NS \\
\hline Penetrating $(\%)$ & 1.8 & 2.6 & NS \\
\hline Antiplatelet argent (\%) & 7 & 0 & NS \\
\hline Anticoagulant argent $(\%)$ & 3.5 & 2.6 & NS \\
\hline Liver disease $(\%)$ & 0.9 & 0 & NS \\
\hline ABC score, median (IQR) & $0(0$ to 0$)$ & $1(0$ to 2$)$ & $<0.0001$ \\
\hline TASH score, median (IQR) & $3(1$ to 4$)$ & $8(5$ to 13$)$ & $<0.0001$ \\
\hline INR, median (IQR) & 1.07 (1 to 1.17$)$ & $1.2(1.05$ to 1.43$)$ & $<0.001$ \\
\hline APTT (s), median (IQR) & $25.9(23.9$ to 28.7$)$ & 28.3 (25.8 to 37$)$ & $<0.01$ \\
\hline Fbg (mg/dL), median (IQR) & 241 (191 to 311$)$ & 167 (96 to 205$)$ & $<0.0001$ \\
\hline PRBCs within 24 h U, median (IQR) & $0(0$ to 3$)$ & $12(10$ to 20$)$ & $<0.0001$ \\
\hline FFP within $24 \mathrm{~h} \mathrm{U}$, median (IQR) & $0(0$ to 0$)$ & $10(5$ to 15$)$ & $<0.0001$ \\
\hline PC within $24 \mathrm{~h} \mathrm{U}$, median (IQR) & $0(0$ to 0$)$ & $10(0$ to 10$)$ & $<0.0001$ \\
\hline Pelvic external rotation $(\%)$ & 4.4 & 15.4 & $<0.05$ \\
\hline Thoracotomy (\%) & 0.9 & 12.8 & $<0.01$ \\
\hline Laparotomy (\%) & 2.6 & 7.7 & NS \\
\hline Craniotomy (\%) & 21.1 & 23.1 & NS \\
\hline $\operatorname{IVR}(\%)$ & 2.6 & 20.5 & $<0.001$ \\
\hline 24-h mortality (\%) & 5.3 & 38.5 & $<0.0001$ \\
\hline 28-day mortality (\%) & 6.1 & 46.2 & $<0.0001$ \\
\hline
\end{tabular}

$M T$ massive transfusion, $I Q R$ interquartile range, $S B P$ systolic blood pressure, $H R$ heart rate, ISS injury severity score, FAST focused assessment with sonography for trauma, $H b$ hemoglobin, $B E$ base excess, $A B C$ score assessment of blood consumption score, TASH score trauma-associated severe hemorrhage score, INR international normalized ratio, APTT activated partial thromboplastin time, Fbg fibrinogen, $P R B C$ s packed red blood cells, $F F P$ fresh-frozen plasma, $P C$ platelet concentrates, IVR interventional radiology one, intra-abdominal hemorrhage secondary to liver injury in another one, and an unstable pelvic fracture in the other.

The RR, HR, ISS, FAST positive rate, UPF rate, ABC score, TASH score, INR, APTT, blood transfusion number (PRBCs, FFP, PC), pelvic external rotation rate, thoracotomy rate, laparotomy rate, IVR rate, $24 \mathrm{~h}$ mortality, and 28-day mortality were all significantly higher in the MT group. However, the ratio of male patients as well as SBP, $\mathrm{Hb}, \mathrm{BE}$, and Fbg levels were significantly lower in the MT group.

We evaluated the predictors of MT using a univariate logistic regression model, which revealed gender (male),
HR ( $>120 / \mathrm{min}$.$) , SBP (<90 mmHg), FAST positivity, UPF$ positivity, $\mathrm{Hb}, \mathrm{BE}$, and Fbg levels as useful predictors for MT (Table 2). We then performed multiple logistic regression modeling analysis. Explanatory values were selected by the significant predictors for MT in univariate analysis, which included gender, HR (<120/min vs. 120/min), SBP $(<90 \mathrm{mmHg}$ vs. $90 \mathrm{mmHg}$ ), FAST (positivity vs. negativity), UPF (positivity vs. negativity), $\mathrm{Hb}(\mathrm{g} / \mathrm{dL}), \mathrm{BE}$ $(\mathrm{mmol} / \mathrm{L})$, and $\mathrm{Fbg}(\mathrm{mg} / \mathrm{dL})$. From this result, a low level of Fbg and BE were independent predictors of MT $(p<0.01$, $p<0.05$, respectively; Table 3 ). 
Table 2 Univariate logistic regression model for the predictors of massive transfusion

\begin{tabular}{lllr}
\hline Variables of ABC and TASH scores & \multicolumn{1}{c}{$p$ value } & OR & \multicolumn{1}{c}{$95 \%$ CI } \\
\hline Sex (male vs. female) & $<0.01$ & 0.355 & $0.166-0.751$ \\
Mechanism (penetrating vs. blunt) & NS & 1.474 & $0.067-15.799$ \\
Heart rate $(\geq 120 /$ min vs. $<120 / \mathrm{min})$ & $<0.001$ & 6.005 & $12.170-17.692$ \\
Systolic blood pressure (<90 vs. $\geq 90 \mathrm{mmHg})$ & $<0.001$ & 0.193 & $0.072-0.501$ \\
Focused assessment with sonography for trauma (positive vs. negative) & $<0.01$ & 3.571 & $1.490-8.589$ \\
Unstable pelvic fracture (positive vs. negative) & $<0.001$ & 6.207 & $2.129-19.606$ \\
Femur fracture open/dislocated (positive vs. negative) & $\mathrm{NS}$ & 3.206 & $0.846-12.173$ \\
Hb (mg/dL) & $<0.0001$ & 0.716 & $0.605-0.834$ \\
$\mathrm{BE}(\mathrm{mmol} / \mathrm{L})$ & $<0.0001$ & 0.767 & $0.681-0.847$ \\
Fbg (mg/dL) & $<0.0001$ & 0.987 & $0.981-0.992$ \\
\hline
\end{tabular}

$M T$ massive transfusion, $O R$ odds ratio, $C I$ confidence interval, $H b$ hemoglobin, $F b g$ fibrinogen, $B E$ base excess
Table 3 Multiple logistic regression model for the predictors of massive transfusion

\begin{tabular}{llll}
\hline Variables & $p$ value & OR & $95 \%$ CI \\
\hline $\mathrm{BE}(\mathrm{mmol} / \mathrm{L})$ & $<0.05$ & 0.855 & $0.745-0.971$ \\
$\mathrm{Fbg}(\mathrm{mg} / \mathrm{dL})$ & $<0.01$ & 0.992 & $0.986-0.998$ \\
\hline
\end{tabular}

Other variables entered in the model were: sex, systolic blood pressure (SBP) $<90$ vs. $\geq 90 \mathrm{mmHg}$, focused assessment with sonography for trauma (FAST) positive vs. negative, heart rate (HR) $<120 / \mathrm{min}$ vs. $\geq 120 / \mathrm{min}$, base excess $(\mathrm{BE})(\mathrm{mmol} / \mathrm{L})$, unstable pelvic fracture (UPF) positive vs. negative, hemoglobin $(\mathrm{Hb})(\mathrm{mg} / \mathrm{dL})$

$M T$ massive transfusion, $O R$ odds ratio, $C I$ confidence interval, $B E$ base excess, $F b g$ fibrinogen

Finally, we performed the receiver operating characteristics (ROC) analysis, and calculated the area under the curve (AUC) to clarify which factor is the most useful predictor for MT. The highest AUC was achieved for BE (0.845) followed by the TASH score $(0.833)$, Fbg $(0.765)$, and then the ABC score (0.716). The optimal cutoff values for BE and $\mathrm{Fbg}$ were $-1.4 \mathrm{mmol} / \mathrm{L}$ and $211 \mathrm{mg} / \mathrm{dL}$, respectively. According to the AUC value, TASH and BE were significantly higher than the $\mathrm{ABC}$ score $(p<0.01, p<0.01$, respectively; Table 4), but not the Fbg level.

\section{Discussion}

Our study demonstrated that low levels of Fbg and BE were independent predictors of the need for MT in patients who have suffered severe blunt trauma. Both Fbg and BE levels are easy to measure and are already recognized as global markers. Consequently, there are already a few models being used to predict the need for MT, including the ABC score [9] and the TASH score [10]. However, these scoring systems include several variables, such as age, sex, vital signs, FAST, UPF, $\mathrm{Hb}$, and $\mathrm{BE}$, and require considerable time and effort to calculate the score. Hence, a simpler and faster indicator for MT in patients with active bleeding is needed.

This study showed that not only the BE level but also the Fbg level are independent predictive factors for MT. Recently, Yumoto et al. [20] reported that the BE level was a useful predictor of MT, while Soderlund et al. [21] found that mortality after blunt thoracic injury was closely associated with the BE level on admission. Some investigators also proposed that measures of hypoperfusion, such as lactate or BE levels, should be incorporated into the MT scoring systems [10, 22]. In fact, several studies about MT scoring systems have concluded that BE levels or serum

Table 4 Results of receiver operating characteristics analysis for massive transfusion

\begin{tabular}{llllllll}
\hline Variables & AUC & $95 \%$ CI & $\begin{array}{l}\text { Optimal } \\
\text { cutoff value }\end{array}$ & Sensitivity & Specificity & $\begin{array}{l}\text { Positive predict } \\
\text { value }\end{array}$ & $\begin{array}{l}\text { Negative predict } \\
\text { value }\end{array}$ \\
\hline ABC score & 0.724 & $0.628-0.803$ & 1 & 64 & 78 & 25 & 89 \\
TASH score & $0.833^{*}$ & $0.744-0.895$ & 5 & 77 & 77 & 30 & 88 \\
Fbg (mg/dL) & 0.765 & $0.683-0.898$ & 211 & 78 & 65 & 34 & 81 \\
BE (mmol/L) & $0.845^{*}$ & $0.683-0.848$ & -1.4 & 80 & 67 & 31 & 76 \\
\hline
\end{tabular}

$R O C$ receiver operating characteristics, $M T$ massive transfusion, $A U C$ area under the curve, $C I$ confidence interval, $A B C$ assessment blood consumption, $T A S H$ trauma-associated severe hemorrhage, $F b g$ fibrinogen, $B E$ base excess

$* p<0.01$ vs. ABC score 
lactate concentrations should be adopted as a component of the prediction of MT [10, 20, 22]. These reports strongly supported our results.

On the other hand, Fbg plays an essential role in the hemostatic coagulation systems linked to activated platelets and the formation of a fibrin network [23]. Additionally, a decrease in Fbg was more rapid than that in any other coagulation factor when plasma-poor blood transfusion or extracellular fluids were infused in patients with major blood loss [24]. When the Fbg level falls to $40 \%$ of the normal level, a bleeding tendency ensues. On the other hand, a bleeding tendency does not develop when other coagulation factors (prothrombin, factor V, factor VII) fall to about $20 \%$ of normal [24]. Inaba et al. [25] reported that the Fbg level increase correlates with improved survival rates for patients who required MT. Furthermore, they concluded that an Fbg level $<100 \mathrm{mg} /$ $\mathrm{dL}$ was a strong independent risk factor for death. It is well known that maintaining a high Fbg level improves the survival rate, but our study also suggests that the Fbg level is one of the most important predictors of the need for MT, in comparison with other coagulation factors, in trauma patients.

Our study demonstrated that the optimal cutoff value for the Fbg level on admission was $211 \mathrm{mg} / \mathrm{dL}$ (normal range $200-400 \mathrm{mg} / \mathrm{dL}$ with up to a 10 -fold increase during tissue damage, infection, and cytokine-induced inflammatory responses [26], and with less than $100 \mathrm{mg} / \mathrm{dL}$ of Fbg predictive of microvascular bleeding [24]). Fenger-Eriksen et al. [26] reported that patients with serious bleeding, in whom a fibrinogen concentrate had been administered to treat hypofibrinogenaemia (defined by a laboratory threshold value below $200 \mathrm{mg} / \mathrm{dL}$ ) had significantly less blood loss and transfusion requirements (RBC, FFP and platelets). This threshold is similar to that according to our results, which revealed that the level of Fbg for MT was less than $211 \mathrm{mg} / \mathrm{dL}$ in blunt trauma patients at the time of admission.

We included in our MT group, three patients who died of uncontrolled massive bleeding within $24 \mathrm{~h}$. The Fbg levels were already extremely low in all three on arrival (89, $50,163 \mathrm{mg} / \mathrm{dL}$, respectively). This also suggested that a low Fbg level on admission might predict the clinical outcome of trauma patients.

In Japan, a portable Fbg analyzer CG02N (A\&T Corporation, Kanagawa, Japan) has recently become available for clinical use. With this device, the Fbg level in a blood sample is available in about $1 \mathrm{~min}$. We consider this mobile Fbg analyzer as a point of care testing in the emergency room and the bedside in the intensive care unit (ICU). We will attempt to validate the results of this study in relation to the usefulness of the Fbg level as predictor for MT by using CG02N in the near future.
This study has some limitations. First, it was retrospective and the sample size was small. Second, we did not consider the presence of severe head injury, although Lee et al. [27] reported recently that traumatic brain injury was not independently associated with more profound coagulopathy. Third, we could not examine the potential influence of the patient's transport time and the fluids administered prior to admission to our center. Fourth, in this study we examined Fbg levels on admission only.

\section{Conclusions}

This study demonstrated that Fbg and BE levels as a single factor could predict the need for MT. We recommend that Fbg and BE levels be measured on admission and as point of care testing, especially in patients who have suffered blunt trauma.

Acknowledgments We thank Ms. Kanae Misumi of the Department of Emergency and Critical Care Medicine, Faculty of Medicine, Fukuoka University for her help in data encoding.

\section{Compliance with ethical standards}

Conflict of interest We have no conflicts of interest to declare.

Open Access This article is distributed under the terms of the Creative Commons Attribution 4.0 International License (http://creativecommons.org/licenses/by/4.0/), which permits unrestricted use, distribution, and reproduction in any medium, provided you give appropriate credit to the original author(s) and the source, provide a link to the Creative Commons license, and indicate if changes were made.

\section{References}

1. Bellamy RF. The causes of death in conventional land warfare: implications for combat casualty care research. Mil Med. 1984;149:55-62.

2. Holcomb JB, McMullin NR, Pearse L, Caruso J, Wade CE, Oetjen-Gerdes L, et al. Causes of death in U.S. Special Operations Forces in the global war on terrorism: 2001-2004. Ann Surg. 2007;245:986-91.

3. Sauaia A, Moore FA, Moore EE, Moser KS, Brennan R, Read RA, et al. Epidemiology of trauma deaths: a reassessment. J Trauma. 1995;38:185-93.

4. Peng R, Chang C, Gilmore D, Bongard F. Epidemiology of immediate and early trauma deaths at an urban Level I trauma center. Am Surg. 1998;64:950-4.

5. MacLeod JB, Cohn SM, Johnson EW, McKenney MG. Trauma deaths in the first hour: are they all unsalvageable injuries? Am J Surg. 2007;193:195-9.

6. Demetriades D, Murray J, Charalambides K, Alo K, Velmahos G, Rhee P, et al. Trauma fatalities: time and location of hospital deaths. J Am Coll Surg. 2004;198:20-6.

7. Como JJ, Dutton RP, Scalea TM, Edelman BB, Hess JR. Blood transfusion rates in the care of acute trauma. Transfusion. 2004;44:809-13. 
8. Malone DL, Dunne J, Tracy JK, Putnam AT, Scalea TM, Napolitano LM. Blood transfusion, independent of shock severity, is associated with worse outcome in trauma. J Trauma. 2003;54:898-905 (discussion 905-7).

9. Nunez TC, Voskresensky IV, Dossett LA, Shinall R, Dutton WD, Cotton BA. Early prediction of massive transfusion in trauma: simple as $\mathrm{ABC}$ (assessment of blood consumption)? J Trauma. 2009;66:346-52.

10. Yucel N, Lefering R, Maegele M, Vorweg M, Tjardes T, Ruchholtz S, et al. Trauma Associated Severe Hemorrhage (TASH)Score: probability of mass transfusion as surrogate for life threatening hemorrhage after multiple trauma. J Trauma. 2006;60:1228-36 (discussion 36-7).

11. Ciavarella D, Reed RL, Counts RB, Baron L, Pavlin E, Heimbach DM, et al. Clotting factor levels and the risk of diffuse microvascular bleeding in the massively transfused patient. Br J Haematol. 1987;67:365-8.

12. Schreiber MA, Perkins J, Kiraly L, Underwood S, Wade C, Holcomb JB. Early predictors of massive transfusion in combat casualties. J Am Coll Surg. 2007;205:541-5.

13. Mardel SN, Saunders FM, Allen H, Menezes G, Edwards CM, Ollerenshaw L, et al. Reduced quality of clot formation with gelatin-based plasma substitutes. Br J Anaesth. 1998;80:204-7.

14. Murray DJ, Pennell BJ, Weinstein SL, Olson JD. Packed red cells in acute blood loss: dilutional coagulopathy as a cause of surgical bleeding. Anesth Analg. 1995;80:336-42.

15. Chambers LA, Chow SJ, Shaffer LE. Frequency and characteristics of coagulopathy in trauma patients treated with a low- or high-plasma-content massive transfusion protocol. Am J Clin Pathol. 2011;136:364-70.

16. Stinger HK, Spinella PC, Perkins JG, Grathwohl KW, Salinas J, Martini WZ, et al. The ratio of fibrinogen to red cells transfused affects survival in casualties receiving massive transfusions at an army combat support hospital. J Trauma. 2008;64:S79-85 (discussion S85).

17. Kudo D, Sasaki J, Akaishi S, Yamanouchi S, Koakutsu T, Endo T, et al. Efficacy of a high FFP:PRBC transfusion ratio on the survival of severely injured patients: a retrospective study in a single tertiary emergency center in Japan. Surg Today. 2014;44:653-61.
18. Davis JW, Shackford SR, Mackersie RC, Hoyt DB. Base deficit as a guide to volume resuscitation. J Trauma. 1988;28:1464-7.

19. Kutcher ME, Kornblith LZ, Narayan R, Curd V, Daley AT, Redick BJ, et al. A paradigm shift in trauma resuscitation: evaluation of evolving massive transfusion practices. JAMA Surg. 2013;148:834-40.

20. Yumoto T, Iida A, Hirayama T, Tsukahara K, Shiba N, Yamanouchi $\mathrm{H}$, et al. Immediate screening method for predicting the necessity of massive transfusions in trauma patients: a retrospective single-center study. J Intensive Care. 2014;2:54.

21. Söderlund T, Ikonen A, Pyhältö T, Handolin L. Factors associated with in-hospital outcomes in 594 consecutive patients suffering from severe blunt chest trauma. Scand J Surg. 2015;104:115-20.

22. Ogura T, Nakamura $Y$, Nakano $M$, Izawa $Y$, Nakamura $M$, Fujizuka K, et al. Predicting the need for massive transfusion in trauma patients: the Traumatic Bleeding Severity Score. J Trauma Acute Care Surg. 2014;76:1243-50.

23. Sorensen B, Larsen OH, Rea CJ, Tang M, Foley JH, FengerEriksen C. Fibrinogen as a hemostatic agent. Semin Thromb Hemost. 2012;38:268-73.

24. Hiippala ST, Myllyla GJ, Vahtera EM. Hemostatic factors and replacement of major blood loss with plasma-poor red cell concentrates. Anesth Analg. 1995;81:360-5.

25. Inaba K, Karamanos E, Lustenberger T, Schochl H, Shulman I, Nelson J, et al. Impact of fibrinogen levels on outcomes after acute injury in patients requiring a massive transfusion. J Am Coll Surg. 2013;216:290-7.

26. Fenger-Eriksen $C$, Lindberg-Larsen $M$, Christensen AQ, Ingerslev J, Sorensen B. Fibrinogen concentrate substitution therapy in patients with massive haemorrhage and low plasma fibrinogen concentrations. Br J Anaesth. 2008;101:769-73.

27. Lee TH, Hampton DA, Diggs BS, McCully SP, Kutcher M, Redick BJ, et al. Traumatic brain injury is not associated with coagulopathy out of proportion to injury in other body regions. $\mathbf{J}$ Trauma Acute Care Surg. 2014;77:67-72 (discussion 72). 